\title{
The Impact of Demographic Structure on Housing Prices: Evidence from Macau \\ Song Yanan, ${ }^{1, *}$
}

\author{
${ }^{1}$ School of Business of Macau University of Science and Technology, Macau \\ *ynsong@must.edu.mo
}

\begin{abstract}
Due to the Macau's rapid development of the real estate market, the average housing prices increased by about $600 \%$ in 10 years. The changes in the demographic structure also affected the housing needs, and the aging population increased to affect the housing market. Therefore this paper used the quarterly data from 2005 to 2015 to analyzed the impact of demographic structure on housing price in Macau. The results showed the ratio of the aging ratio, child dependency ratio, marital status and GDP had significant impact on the housing prices in Macau. It is necessary to improve the relevant policies to meet the housing needs of the residents in accordance with the demographic changes and population flows. Especially the government needs to pay attention to the trend of aging population, and improve the housing quality and living environment of Macau.
\end{abstract}

Keywords: Demographic Structure, Housing Price, Hedonic Price Method, Aging Population, Macau

\section{Introduction}

With the rapid growth of national housing prices in recent years, Macau as one of China's most economically developed regions, its real estate market has become the focus of social debate. From 2005 to 2015, Macau's the housing prices have increased by about $600 \%$ in 10 years, according to the data from DSEC.

As the housing demand is more related to family needs rather than individuals, so the impact of housing demand is not just based on population factor, such as gender, family structure, occupation and age which are important factors affecting housing demand. The population of Macau has changed from a youth-oriented population to an old-aged population. And the aging index had reached 30.8\% in 2000 according to DSEC. The rapid demographic transition also had a huge impact on Macau's socio-economic development. Since the reunification, there have been many new features in the demographic structure of Macau, such as the aging population, the increase of marriage rate, the improvement of education, the diversification of occupational and industrial structure, and the increase in the number of foreign employees.

Based on the previous research, the study of housing price from the population perspective is relatively few, most of the study focus on the population factors. Green and Hendershott (1996) used the census data to analyze the impact of age structure, education, and income on homogeneous housing prices, and found that the age structure of the population had a slight positive effect on housing prices. Li (2000) studied the second-hand housing market. The results showed that different consumers have different impacts on different types of housing, married people with families and children, and those with higher social status had a greater impact on the second-hand real estate market. Saiz (2003) investigated the impact of immigration on the price of Miami residences after the 1980s' "Marley Incident" and set up three control groups as an experiment. The study concluded that in the short run, the impact of foreign immigrants on the local housing market will be significant, and mostly on the housing rents. In the long term, residential prices will rise by $1.5 \%$ for every $1 \%$ increase in the immigrants.Wu (2009) studied the choice of houses purchase or lease. The results showed that the age and educational background, marital status, household size, and labor force in a household had impact on the choice of tenants and thus affected the rental and purchase price of the house. Crespi (2010) argued that moderately lowering the restrictions of immigration and welcoming foreign sellers or immigrants who come to the US to buy a house will have the power to stabilize the US housing market. Chen et al. (2012) found that the population structure had a decisive impact on China's housing demand. China's housing prices did not rise rapidly in the long run, but rose sharply 
in 2004 which due to the transformation of the population structure. The baby boom in 1981 and the rising labor force share in 2004 could be the explanation. The impact of newborns on housing demand is not significant, but the housing demand of population over 20 years were the highest, which began to decline after 50 years. The authors believed that why aging population had a negative impact on housing prices was related to the economic and educational standards of the elderly, which was the impact of income on housing demand. Ding (2012) analyzed the relationship between population structure and housing price using the fixed effect model. The empirical results show that the population size, the elder dependency ratio and the family size had influences on housing price. Chang (2013) argued that industry income and occupational composition will affect the economic affordability of housing prices for different groups of people. From 2004 to 2011, housing price surged in Macau. Governments and institutions should improve the housing prices of different populations by providing assistance in mortgage payments and taxations. Latif (2015) used Canadian provincial panel data to examine the impact of new immigrants on rents between 1983 and 2010, using metrological methods such as the unit root method, cointegration regression, and correction error models in his study. Both of the two least squares models show that immigration has a significant positive correlation with rents, and this effect occurs both in the short and long term.

Based on the current research, the change of demographic structure might increase the demand for real estate and housing price. However, different regions show positive or none relations of these factors in the use of relevant data. And the studies of Macau's housing prices have focused on government policies, the impact of changes in economic indicators, or the impact of housing-related features on prices. Few scholars have analyzed the linkages between population factors and housing prices in Macau. Therefore, this paper will analyze the relations between Macau demographic structure and housing prices to explore some neglected factors on housing price in Macau.

In view of the availability and applicability of the data, this paper chooses the characteristic price model to study the impact of the demographic structure on the housing price in Macau by using Macau's quarterly data from 2005 to 2015. And the demographic structure would be measured by natural structure such as marital status, child dependency ratio, aging ratio, and the economic structure such as the proportion of employment in gambling industry and foreign workers etc.

\section{Hypothesis}

The elders above 65 years old in Macau are more likely have higher savings. These elders are more willing to make investments in the real estate and to use savings to buy property for compensation of the low pension and provide for the future.

\section{Hypothesis 1. Aging ratio (AG) has a positive effect on housing price (HP)}

The child dependency ratio represents the composition of family members in a region. And the higher the proportion of children, the heavier the economic burden of a family, which might lower the demand for the houses which are high-priced. Especially the average housing price in Macau is very high.

\section{Hypothesis 2. Child dependency ratio (CD) has a negative effect on housing price (HP)}

When the number of new married is increasing, the new family will live independently. These new families will create the new demand for housing, the housing price will rise accordingly.

\section{Hypothesis 3. Marital status (MAG) has a positive effect on housing price (HP)}

As the pillar industry of Macau's economy, the gambling industry has an irreplaceable impact on the development of Macau's society and on the supply of land and labor forces. The employment income of gambling industry usually are higher than the other industries and absorb a lot of employment. Thus the proportion of high income employment in gambling industry will also push the housing prices in Macau.

\section{Hypothesis 4. The proportion of employment in gambling industry (GAP) has a positive effect on housing price (HP)}

In Macau, there are some argues about the demand for the local housing market is squeezed by the foreign labors. Based on the supply and demand theory, when the population is increasing by foreign labors, if the supply of housing in Macau would not change, the housing price will increase. 


\section{Hypothesis 5. The proportion of foreign employment (FL) has a positive effect on housing price (HP)}

\section{Model and Data}

In order to obtain more accurate results, this paper will use the general linear regression and semi-logarithm regression model and compare the results.

$$
\begin{aligned}
& H P=\alpha+\beta_{1} A G+\beta_{2} C D+\beta_{3} M A G+\beta_{4} G A P+\beta_{5} F L+\beta_{6} C A M+\beta_{7} G D P \\
& L n(H P)=\alpha+\beta_{1} A G+\beta_{2} C D+\beta_{3} M A G+\beta_{4} G A P+\beta_{5} F L+\beta_{6} C A M+\beta_{7} G D P
\end{aligned}
$$

HP indicates the housing price, which is measured by the average transaction price per unit of mop/ $\mathrm{m}^{2}$. AG indicates aging ratio, which is measured by the proportion of the population aged 65 or above to the total population of Macau. CD indicates the child dependency ratio, which is measured by the percentage of the population aged 15 and below in Macau is to the population aged 16-64 years old. MAG indicates the marital status, which is measured by the number of registered marriages per quarter. GAP and FL indicate the proportion of employment in gambling industry and the proportion of foreign labors. CAM and GDP are control variables, which is measured by the gaming revenues and growth rate of gross domestic production. All the data are quarterly from 2005 to 2015 and come from DSEC.

In this paper, the EVIEWS 8.0 method is used to adjust the dependent variable and other independent variables to eliminate the seasonal fluctuation. Therefore, the model with " $s a$ " in this paper represents the seasonal adjustment for the variables which could eliminate the fluctuations of time series and show the potential trend of the sequence cycle component. The trend of economic cycle can reflect the real rules of the broad movement. For the GDP, this paper uses the addition rule to eliminate fluctuations. For the rest of the variables, uses the rule of multiplication. And after conducting unit root test, at the 5\% significance level which included intercept and trend items, HP, AG, CD, GDP had past ADF Test and PP Test respectively; at the 5\% significance level which included intercept items without trend items, LNHP, MAG, GAP and CAM, FL past ADF Test and PP Test respectively. Thus all variables are first order stationary and we could conduct the regressions.

\section{Empirical Results}

After the stepwise regression, Model VI shows better explanatory ability for variables. The coefficients of age, child dependency ratio are $0.4230,-0.3093$ and significant at $1 \%$ level respectively, which mean that 1 unit of increase in aging ratio will cause $42.3 \%$ of increase in Macau housing prices, and 1 unit of increase in child dependency ratio will cause $30.93 \%$ of decrease in Macau housing. Unexpectedly, the variable of marital status shows a positive effect on housing prices with a coefficient of 0.0014 , indicating a lunit of increase of married couples will cause $0.14 \%$ increase in housing prices which has a very slight impact on the housing price. And the proportion of employment in gambling industry and the proportion of foreign labors are not significant. GDP shows a significant positive impact on the housing price, which means that the change of the GDP will lead to the social and economic fluctuation including the living standard and the income level. When GDP increases faster, housing price of Macau rises faster.

All the model is tested by autocorrelation, heteroskedasticity, multicollinearity and residual normal distribution test. Finally, after eliminating the relevant variables that are not significant and failing to test, this paper find that there are still four variables, the aging ratio, child dependency ratio, marital status and GDP growth rate, having significant impact on housing prices, which is consistent with the Hypothesis 1, 2,3.

The proportion of the elders over 65 of Macau is $8.98 \%$ of total population. As the population of this part increases, the social impact will gradually increase. Moreover, based on Macau social security system and the central savings system, the impact of the elders over the age of 65 on housing prices in Macau will be larger than other regions with better pension system. The impact of the child 
dependency ratio indicates that the increase of the proportion of the population under the age of 15 will increase the economic burden of families and affect the family's home purchase decisions, so as to bring a negative impact on housing prices. GDP still plays the most important role on housing prices. As for the the proportion of employment in gambling industry and the proportion of foreign

Table 1 Empirical Results

\begin{tabular}{|c|c|c|c|c|c|c|}
\hline & $\overline{I I}$ & II & IIII & IV & $\overline{\mathrm{V}}$ & $\overline{\mathrm{VI}}$ \\
\hline & HP_sa & Ln (hp_sa) & HP_sa & Ln(hp_sa) & Hp_sa & Ln (hp_sa) \\
\hline $\boldsymbol{A G}$ & $\begin{array}{c}-461.6861 \\
(-0.05) \\
\end{array}$ & $\begin{array}{l}-0.2820 \\
(-1.39) \\
\end{array}$ & $\begin{array}{c}23472.76^{* *} \\
(2.12) \\
\end{array}$ & $\begin{array}{c}0.0391 * * * \\
(4.35) \\
\end{array}$ & $\begin{array}{c}23636.41^{* * * *} \\
(3.16) \\
\end{array}$ & $\begin{array}{c}0.4230^{* * * *} \\
(5.23)\end{array}$ \\
\hline$C D$ & & & $\begin{array}{c}-11553.57 * * \\
(-2.67)\end{array}$ & $\begin{array}{c}-0.1803 * * * \\
(-4.23)\end{array}$ & $\begin{array}{c}-14882.05^{* * *} \\
(-4.39)\end{array}$ & $\begin{array}{c}-0.3093 * * * \\
(-5.59)\end{array}$ \\
\hline MAG & & & $\begin{array}{c}37.5470 \\
(1.57)\end{array}$ & $\begin{array}{l}0.0011 \\
(1.32) \\
\end{array}$ & $\begin{array}{c}49.3401 * * \\
(2.23)\end{array}$ & $\begin{array}{c}0.0014 * * \\
(2.11) \\
\end{array}$ \\
\hline GAP & & & $\begin{array}{c}50.9829 \\
(0.05)\end{array}$ & $\begin{array}{c}-0.0096 \\
(-0.31) \\
\end{array}$ & & \\
\hline FL & $\begin{array}{c}16.7052 \\
(0.79)\end{array}$ & $\begin{array}{c}5.29 \mathrm{E}-06 \\
(0.01)\end{array}$ & $\begin{array}{c}15.3738 \\
(0.94)\end{array}$ & $\begin{array}{c}0.0002 \\
(0.49)\end{array}$ & & \\
\hline GAM & & & $\begin{array}{c}0.3508^{*} \\
(1.77)\end{array}$ & $\begin{array}{c}\text { 7.23E-06* } \\
(1.90)\end{array}$ & $\begin{array}{c}0.3508^{*} \\
(1.77)\end{array}$ & $\begin{array}{c}\text { 7.23E-06* } \\
(1.90)\end{array}$ \\
\hline GDP & $\begin{array}{l}-23.6510 \\
(-0.1856) \\
\end{array}$ & $\begin{array}{c}27.0015 \\
(0.35) \\
\end{array}$ & & & $\begin{array}{c}93.5594 * * * \\
(2.84) \\
\end{array}$ & $\begin{array}{c}86.0048^{* *} \\
(2.41) \\
\end{array}$ \\
\hline C & $\begin{array}{c}182557.0 \\
(0.41)\end{array}$ & $\begin{array}{c}19.3180 \\
(1.28)\end{array}$ & $\begin{array}{c}20105.94 \\
(0.46)\end{array}$ & $\begin{array}{c}10.0224^{* * *} \\
(9.78) \\
\end{array}$ & $\begin{array}{c}-7941.708 \\
(-0.05)\end{array}$ & $\begin{array}{c}10.4346^{* * *} \\
(3.79) \\
\end{array}$ \\
\hline AR(1) & $\begin{array}{c}0.9877 * * * \\
(29.19)\end{array}$ & $\begin{array}{c}0.9902 * * * \\
(44.99)\end{array}$ & $\begin{array}{c}0.9086^{* * *} \\
(21.9)\end{array}$ & $\begin{array}{c}0.7763 * * * \\
(7.51) \\
\end{array}$ & $\begin{array}{c}0.8686^{* * *} \\
(20.18)\end{array}$ & $\begin{array}{c}0.8050 * * * \\
(9.34)\end{array}$ \\
\hline F-stat & $228.793 * * *$ & $374.000 * * *$ & $252.156^{* * *}$ & $415.028^{* * * *}$ & $199.405^{* * *}$ & $319.872 * * *$ \\
\hline $\mathbf{R}^{2}$ & 0.968670 & 0.980598 & 0.976758 & 0.985749 & 0.985539 & 0.985609 \\
\hline Adjusted $\mathbf{R}^{2}$ & 0.964436 & 0.977976 & 0.972885 & 0.983374 & 0.970647 & 0.981531 \\
\hline D-W stat & 2.002120 & 1.957371 & 2.126860 & 1.675503 & 2.051572 & 1.837307 \\
\hline
\end{tabular}

labors, although the gambling industry is the pillar industry for Macau and absorbs the most of the residents working in this industry, most of the jobs in gambling industry are unskilled or low technique required. The income of these residents are just relatively higher than other low skill jobs which can't afford the high housing prices. And for the foreign labors, most of them are also low skilled workers and choose to live in Zhuhai for the lower rent costs which won't be the major participants in the local housing market.

\section{Conclusion}

The purpose of this paper is to explore the relations of demographic structure and housing prices in Macau. The characteristic price method is widely used to study the relations between the characteristics of commodities and prices. In this paper, the regression model is used to analyze the demographic structure and housing price of Macau from 2005 to 2015 quarterly and finds the aging ratio, child dependency ratio, marital status and GDP play significant roles on housing price in Macau.

Considering the future development of Macau, due to the aging population and the declining labor force, the changes in the demographic structure of Macau society should be considered, not only about increasing affordable housing, but also about improving the elders live standards. The development history of the housing market in typical economies such as the United States and Japan shows that the change of the total population and structure has the most significant impact on housing demand. In the rapid population growth period, this will lead to an increase in housing market demand, thereby driving the real estate, construction and other related industries, the overall national economy is also in a period of rapid growth. And with the new demographic situation, the trend of housing construction will also change. It is necessary to improve the relevant policies to meet the housing needs of the residents in accordance with the new characteristics of housing demand, demographic changes and population flows. Especially need to pay attention to the trend of aging population, and improve the housing quality and living environment of Macau. 


\section{References}

[1] Richard Green, \& H.Hendershott, P.. Age, housing demand, and real house prices. Regional Science and Urban Economics, 26 (1996), p. 465-480.

[2] Li, SI-MENG. The Housing Market and Tenure Decisions in Chinese Cities A Multivariate Analysis of the Case of Guangzhou. Housing Studies, 15(2000), p. 213-236.

[3] Saiz, A. Room in the Kitchen for the Melting Pot: Immigration and Rental Prices. Review of Economics and Statistics, 85(3) (2003), p. 502-521.

[4] Wu. The Choice of Urban Family Housing Consumption- An Example of Hangzhou. Zhejiang University (2009).

[5] Crespi, G. S. Green Cards for Foreign House Buyers : A Way to Help Stabilize Housing Prices. Tulsa Law Review, 45(3) (2010).

[6] Chen et al. Demographic Transition and Housing Demand in China: 1999 - 2025. Financial Research, 379 (2012), p. 129-140.

[7] Ding. The Impact of Population Factors on China 's housing prices. Fudan University (2012).

[8] Chang, H.-C. Housing affordability in Macau: evidence and policy. China Economic Journal, 6(1) (2013) , p. 46-56.

[9] Latif, E. Immigration and Housing Rents in Canada:A Panel Data Analysis. Economic Issues, 20 (2015) , p. 91-108.

[10] Tiemei Gao. Econometric Methods and Modeling --- EViews Applications and Examples. Tsinghua University Press(2009). 